\title{
Fraunhofer learns to tighten its belt
}

Munich. Germany's Fraunhofer Society the publicly funded association of 48 applied research institutes - is hoping to benefit directly from the desire of the country's new research minister, Paul Krüger, to see a major shift in government funding from basic to applied research.

Earlier this year, the minister announced that the research budget of his ministry, the BMFT, will be frozen at its current level of about DM9.5 billion (US\$6.0 billion) for the next two years. Included in the freeze is funding for the Fraunhofer institutes, putting greater pressure on them to seek research contracts from the private sector.

But Hans-Jürgen Warnecke, who takes over as president of the society this month, says Krüger has told him in private that he would like to increase the allocation to the Fraunhofer institutes. These are the main recipients of government support for applied research, and the increase would be achieved at the expense of BMFT's support for basic research. At present, about 40 per cent of the BMFT budget goes to basic research. In public, Krüger has said that he intends to maintain this figure. But Warnecke

\section{Fraunhofer to keep}

\section{east German centres}

Munich. The Fraunhofer Society (see story above) has decided to retain all of the institutes - and most of the research groups - that it established in the new Länder immediately after reunification for a three-year trial period.

Shortly after the Berlin Wall came down in October 1989, teams of experts were sent into east Germany to assess the research being done there. At the same time, the Fraunhofer Society began negotiations with the German research ministry (BMFT) to secure the necessary funding to take over the best research.

By 1990, ten institutes, employing 732 staff, had been set up on a trial basis. Seven of the ten will now be taken over fully from the middle of next year; the three others have another two years to run before a decision is made about their future.

In addition, 12 research groups making up a total of 245 scientists and technical staff - were incorporated into institutes in the old Länder in what was formerly West Germany. From next year, ten of the these groups be become full Fraunhofer members.

The Fraunhofer groups in the new Länder have not been slow in attracting industrial funding. Last year, according to the society, they received DM14 million from industry for contract research. A.A. says Krüger would in fact like to see this fall to about one-third, and that there is backing for this view in political circles.

"For example, there are strong opinion leaders in parliament who say that if we can't have more money for research, it should be better distributed, that is with more emphasis on applied research", he says.

Warnecke, who is 59, is a professor at the University of Stuttgart. He has also been head of the Fraunhofer Institute for Manufacturing and Automation in Stuttgart, now the largest in the country, since 1971; Warnecke says that he plans to extend across the whole of the organization the "scientific entrepreneurialism" techniques he has developed at Stuttgart.

He takes over at a time when the institutes are feeling the first real pressure on budgets since the organization was set up in 1949 as part of German's post-war reconstruction. Last year the Fraunhofer institutes in the old Länder had their project funding from the BMFT cut by more than 20 per cent, to DM169 million, although their basic funding was held at DM176 million.

In a bid to make up the shortfall, the various institutes increased their joint income from private contract research from DM183 million in 1991 to DM191 million in 1992. Warnecke believes they will have do even better if they are to survive. But he also believes that the funding shift favoured by Krüger would help.

Warnecke is aware that competition to Fraunhofer institutes for applied research contracts in Germany is not strong at present. Most comes from universities and national research centres, which have much lower overheads than the institutes. But these are only effective in a few areas, such as information processing or laser development.

In future, says Warnecke, the competition is likely to increase. "But we have one thing that universities and basic research centres tend to underestimate", he says. "Our culture of result-orientated work means that, unlike these other institutions, we are used to working to tight time and cost constraints."

The Fraunhofer institutes have a high reputation. But Warnecke is not complacent. In a document Leitbild 2000 (Guidelines 2000) to be published at the end of this month, he emphasizes that the society has a responsibility to develop applied research and development in the service of both industry and society, and is keen to increase the effectiveness with which it meets these goals by applying more market-orientated criteria to evaluate research. Scientists will be given more freedom and responsibility in choosing research projects. In return they will be expected to change research areas quickly in response to industrial and social needs. And their continued employment will depend on their ability to attract funds.

\section{IMAGE UNAVAILABLE FOR COPYRIGHT REASONS}

\section{New president Hans-Jürgen Warnecke} wants more 'scientific entrepreneurialism'

No immediate cuts are expected in research staff. But, says Warnecke, there will be a reduction in the 350 administrators at the society's headquarters in Munich, and more services will be decentralized. Central services that are retained will be made available strictly according to demand: for example, institutes requiring support for patent applications will pay for the service on an $a d$ hoc basis.

Warnecke says he is determined to take tough action against institutes that are not sufficiently effective in attracting contract research funds. Those failing to meet an agreed target for such research will be evaluated by a committee of experts from both within and outside the Fraunhofer Society (One such investigation is already under way and will be completed this year).

Institutes failing to make the grade will be closed. "My style has always been to give scientists the freedom and responsibility they need, while not being afraid to sack those who don't come up to scratch", says Warnecke.

Alison Abbott

\section{Army AIDS vaccine trial faces new block}

Washington. An amendment passed in Congress last week could derail the US Army's proposed $\$ 20$-million clinical trial of the controversial gp 160 AIDS vaccine produced by the Connecticut-based company MicroGeneSys (see Nature 364; 751, 1993). The amendment to the defence appropriations bill, proposed by Henry Waxman (Democrat, California) and passed by the House of Representatives without a vote, gives the Army more time to agree details of the trial with the National Institutes of Health and the Food and Drug Administration.

AIDS activists say that such a renegotiation would effectively scupper the proposed trial, with the $\$ 20$ million it would cost reverting to other Army medical research. The Senate, which initiated the MicroGeneSys trial as part of last year's budget, has yet to give its opinion. C.M. 